
Kidney
Bloód Pressure
Research

\title{
Changes of Serum Calcium, Magnesium and Parathyroid Hormone Induced by Hemodialysis with Citrate-Enriched Dialysis Solution
}

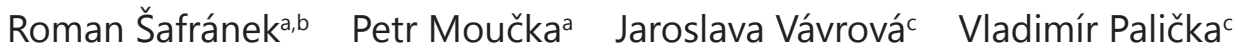 \\ Ladislava Pavlíkovác Sylvie Dusilová Sulkováa,d \\ aHemodialysis Center, University Hospital; ${ }^{b}$ Department of Internal Medicine III; 'Institute of Clinical \\ Biochemistry and Diagnostics; ${ }^{d}$ Department of Internal Medicine II, Charles University, Faculty of \\ Medicine and University Hospital, Hradec Kralove, Czech Republic
}

\section{Key Words}

Citrate - Dialysis solution - Hemodialysis - Calcium - Magnesium • Parathyroid hormone • Hemodiafiltration - Acetate

\begin{abstract}
Background/Aims: In recent years, one of technical attempts to improve biocompatibility and tolerability of the hemodialysis procedure is the substitution of acetate in dialysis solution with citrate. The aim of our study was to compare two dialysis solutions: traditional bicarbonate dialysis solution containing acetate $(3 \mathrm{mmol} / \mathrm{L})$ (solution $\mathrm{A})$; and (solution $\mathrm{C}$ ) commercially produced citrate-enriched bicarbonate dialysis solution $(0.8 \mathrm{mmol} / \mathrm{L}$ citrate). Methods: Patients from a single hemodialysis center $(\mathrm{N}=126)$ were included in the study. Both conventional low-flux hemodialysis and on-line hemodiafiltration procedures were studied. Both dialysis solutions contained identical calcium $(1.5 \mathrm{mmol} / \mathrm{L})$ and magnesium $(0.5 \mathrm{mmol} / \mathrm{L})$ concentrations. Results: Parathyroid hormone (iPTH) concentration decreased during procedures with solution A by $64 \%$. On the contrary, when solution $\mathrm{C}$ was used, iPTH concentration increased insignificantly by $4 \%$. For solution $A$, serum calcium and magnesium increased during procedures in patients with predialysis concentrations lower than 2.33 and $0.76 \mathrm{mmol} / \mathrm{L}$, respectively. In procedures with dialysis solution $C$ these concentrations were significantly lower: $2.19 \mathrm{mmol} / \mathrm{L}$ for $\mathrm{Ca}$ and $0.68 \mathrm{mmol} / \mathrm{L}$ for Mg. Conclusion: Our study clearly shows that the substitution of part of acetate with citrate in dialysis solution significantly influences changes of serum calcium, magnesium and parathyroid hormone concentrations during hemodialysis and hemodiafiltration procedures.
\end{abstract}




\section{Kidney Blood Pressure Research}

Šafránek/Moučka/Vávrová et al.: Citrate-Enriched Hemodialysis Solution

\section{Introduction}

Hemodialysis procedure (HD) has become much safer and better tolerated by patients over the last decades. One of the great technical advances was the replacement of acetate in dialysis solution by bicarbonate as the main buffer in dialysis fluid. Acetate based dialysate was in widespread use in 1980's. Dialysate acetate concentrations were as high as 30-40 $\mathrm{mmol} / \mathrm{L}$, aiming to compensate metabolic acidosis associated with kidney failure. From that time untoward effects of high serum acetate concentrations such as vasodilatation, depressed ventricular function, and hypoxemia are well known [1]. Currently, bicarbonate dialysis solutions with only a low content of acetate $(2-8 \mathrm{mmol} / \mathrm{L})$ in acid concentrate are routinely used. However, significant amounts of acetate may still be delivered into the body in several circumstances, such as in high-volume on-line hemodiafiltration (HDF) with large amounts of substitution fluid prepared on-line from dialysis concentrates. In these cases, acetate load may be associated with potential negative effects [2-3]. In recent years, one of the technical attempts to improve biocompatibility and tolerability of HD procedure was the substitution of acetate in dialysis solution with citrate.

Citric acid is a weak tricarboxylic acid physiologically metabolized to three molecules of bicarbonate by the liver and other organs regardless of the presence of renal failure. It was first used by Ahmad and colleagues to make dialysis solution from dry chemicals [4]. Following its first use, good overall safety has been shown with no changes in predialysis calcium levels [5-6].

Citrate has several advantages over acetate, including local anticoagulant properties that allow a decrease or even removal of anticoagulation for HD, lower peripheral resistance and better blood pressure control during the procedure [6-10]. Another advantage is an increased HD efficiency when citrate dialysate is used [5].

Besides the novel application of citrate in dialysis solution for intermittent hemodialysis, citrate has been traditionally used for regional citrate anticoagulation. During regional anticoagulation citrate infused into the arterial blood line forms stable complexes with ionized calcium $\left(\mathrm{Ca}^{2+}\right)$. Markedly decreased $\mathrm{Ca}^{2+}$ prevents activation of coagulation cascade in the dialyzer. As high doses of citrate are infused into the blood, close monitoring is necessary during the procedure and losses of calcium bound in Ca-citrate are substituted by infusion of calcium into the venous blood line. Compared to heparin, regional citrate anticoagulation abolishes degranulation of polymorphonuclear cells and platelets and reduces oxidative stress during HD [11-12].

Contrary to regional citrate anticoagulation, citrate is not applied into circulation directly, but citrate-enriched dialysis solution is used with only low concentration of citrate. Therefore, neither calcium monitoring nor calcium supplementation is needed. However, despite general acceptance of safety, a higher incidence of intradialytic muscle cramps and postdialysis ionized serum calcium decrease was observed by some authors $[6,10,13]$.

The aim of our study was to compare two dialysis solutions: (a) traditional bicarbonate dialysis solution containing acetate $(3 \mathrm{mmol} / \mathrm{L})$; and (b) a commercially produced citrateenriched bicarbonate dialysis solution $(0.8 \mathrm{mmol} / \mathrm{L}$ citrate $)$ with respect to acute changes of several laboratory parameters induced by procedure. Both dialysis solutions had fixed concentrations of calcium (1.5 mmol/L) and magnesium $(0.5 \mathrm{mmol} / \mathrm{L})$. Serum total and ionized calcium, magnesium, acid-base status and parathyroid hormone changes induced by single hemodialysis (HD) and on-line hemodiafiltration (HDF) procedures in maintenance hemodialysis patients were studied.

\section{Materials and Methods}

Patients

Study cohort involves 126 clinically stable maintenance hemodialysis patients from a single hemodialysis center (median age 67 (56; 75), 81 men, 45 women). All patients were on maintenance dialysis 


\section{Kidney \\ Blood Pressure Research}

Šafránek/Moučka/Vávrová et al.: Citrate-Enriched Hemodialysis Solution

for at least three months, median HD treatment was $33(18 ; 66)$ months. Eighty patients were treated with HD, 46 with HDF. Fifty-six patients ( $45 \%$ ) had diabetes mellitus. The study was a part of a research project approved by a local ethical committee, No. NT/11355-4/2010, 941/09. All procedures were performed in accordance with the Declaration of Helsinki. Informed consent was obtained from each study subject.

\section{Dialysis solution}

Two commercially available dialysis solutions were compared: (a) with acetic acid in concentration of 3 $\mathrm{mmol} / \mathrm{L}$ and bicarbonate concentration $32 \mathrm{mmol} / \mathrm{L}$ (solution A); and (b) with acetic acid $0.3 \mathrm{mmol} / \mathrm{L}$, citrate $0.8 \mathrm{mmol} / \mathrm{L}$, and bicarbonate concentration $32.6 \mathrm{mmol} / \mathrm{L}$ (solution C). Both dialysis solutions contained identical sodium ( $138 \mathrm{mmol} / \mathrm{L})$, diffusible calcium $(1.5 \mathrm{mmol} / \mathrm{L})$, diffusible magnesium $(0.5 \mathrm{mmol} / \mathrm{L})$ and glucose $(1.0 \mathrm{~g} / \mathrm{L})$ concentrations. Potassium concentration was individually adjusted to potassium serum concentrations and varied between 2 - $4 \mathrm{mmol} / \mathrm{L}$.

\section{Dialysis procedure}

Both conventional low-flux hemodialysis and on-line post-dilution hemodiafiltration procedures were studied. Polysulphone dialyzers with identical surface area $1.8 \mathrm{~m}^{2}$ were used for both types of procedures. The ultrafiltration coefficient of low-flux dialyzer for $\mathrm{HD}$ was $14 \mathrm{~mL} / \mathrm{mmHg} / \mathrm{h}$, of high-flux dialyzer for $\mathrm{HDF}$ was $99 \mathrm{~mL} / \mathrm{mmHg} / \mathrm{h}$ (sieving coefficient for beta-2-microglobulin greater than 0.8 ; for albumin lower than 0.001). We used a constant ultrafiltration rate and neither ultrafiltration nor sodium profiling in all procedures. Dialysate temperature was set to $36.0^{\circ} \mathrm{C}$. In HDF, automatic mode of substitution was applied, allowing an achieved high convective volume. Other parameters of HD and HDF than dialysis solutions were kept constant during the study.

\section{Design of the study}

Prior to the study's initiation, patients were dialyzed using either dialysis solution $\mathrm{A}$ or $\mathrm{C}$ as decided by a physician at the beginning of maintenance dialysis treatment. Allocation to HD or HDF was done by a physician according to center rules. During the study period, the mode of extracorporeal treatment was kept constant. To allow a comparison between A and C solutions in cross-over design, patients were switched to the other dialysis solution for a single dialysis treatment. All other technical parameters were kept identical.

Data was collected prospectively once monthly during six months period, always in the first week in given month. Interdialytic intervals in individual patients were constant. Totally, 540 dialysis procedures were studied (334 HD, 206 HDF). Dialysis adequacy using second generation Daugirdas equation was calculated in all of these procedures [14]. Most parameters were evaluated in all procedures. Serum magnesium concentrations and blood pH were measured in $133 \mathrm{HD}$ and $67 \mathrm{HDF}$.

\section{Biochemical analysis}

Serum total calcium (Ca, laboratory reference range 2.15 - $2.55 \mathrm{mmol} / \mathrm{L}$ ), ionized calcium $\left(\mathrm{Ca}^{2+}, 0.9-1.3\right.$ $\mathrm{mmol} / \mathrm{L})$, magnesium ( $\mathrm{Mg}, 0.69-1.05 \mathrm{mmol} / \mathrm{L})$, ionized magnesium $\left(\mathrm{Mg}^{2+}, 0.45-0.6 \mathrm{mmol} / \mathrm{L}\right)$, phosphate (P, mmol/L), urea, and blood $\mathrm{pH}$ were measured before and after HD procedure using routine automatic laboratory methods. Second generation method was used for serum parathyroid hormone concentration measurement (PTH, pmol/L; Immulite Intact PTH, Diagnostic Products Corporation, USA).

Blood was drawn from inserted fistula needle immediately before HD prior to heparin administration and using standardized "slow-flow" method after the end of HD in accordance with KDOQI guidelines [15]. All samples were immediately processed in accordance to institutional standards.

\section{Statistical evaluation}

Results are expressed as median and interquartile range. Wilcoxon matched pairs test was used for paired data and Mann-Whitney U-test for the comparison of independent groups, as appropriate. Data for HD and HDF procedures were analyzed separately. Spearman R was calculated for nonparametric correlations. For calcium and magnesium we used linear regression analysis to calculate "cut-off" concentrations predialysis serum concentration that led to no change of its concentration during HD/HDF treatment. All tests were two-sided and p-value lower than 0.05 was considered to be statistically significant. Statistica 12 (Stat Soft, USA) was used for calculations. 


\section{Kidney \\ Blood Pressure \\ Research}

Table 1. Serum calcium concentrations before and after HD and HDF procedures, comparison of two dialysis solutions: A - Dialysis solution with acetate, $\mathrm{C}$ - dialysis solution with citrate. All calcium concentrations expressed in mmol/L. Ca - total calcium, $\mathrm{Ca}^{2+}-$ ionized calcium concentration. Data are given as median (interquartile range)

\begin{tabular}{lccc}
\hline Serum calcium & \multicolumn{2}{c}{ Dialysis solution } & Difference between \\
concentrations & $\mathrm{A}$ & $\mathrm{C}$ & $\mathrm{groups}$ \\
\hline Ca before procedure & $2.19(2.11 ; 2.27)$ & $2.15(2.04 ; 2.22)$ & $\mathrm{p}<0.001$ \\
Ca after procedure & $2.43(2.35 ; 2.5)$ & $2.23(2.14 ; 2.31)$ & $\mathrm{p}<0.00001$ \\
Ca change & $0.24(0.15 ; 0.32)$ & $0.09(0.01 ; 0.18)$ & $\mathrm{p}<0.00001$ \\
Ca ${ }^{2+}$ before procedure & $1.20(1.14 ; 1.25)$ & $1.19(1.14 ; 1.25)$ & $\mathrm{p}=0.57$ \\
$\mathrm{Ca}^{2+}$ after procedure & $1.40(1.35 ; 1.45)$ & $1.23(1.2 ; 1.27)$ & $\mathrm{p}<0.00001$ \\
$\mathrm{Ca}^{2+}$ change & $0.20(0.15 ; 0.26)$ & $0.05(0.00 ; 0.09)$ & $\mathrm{p}<0.00001$ \\
\hline
\end{tabular}

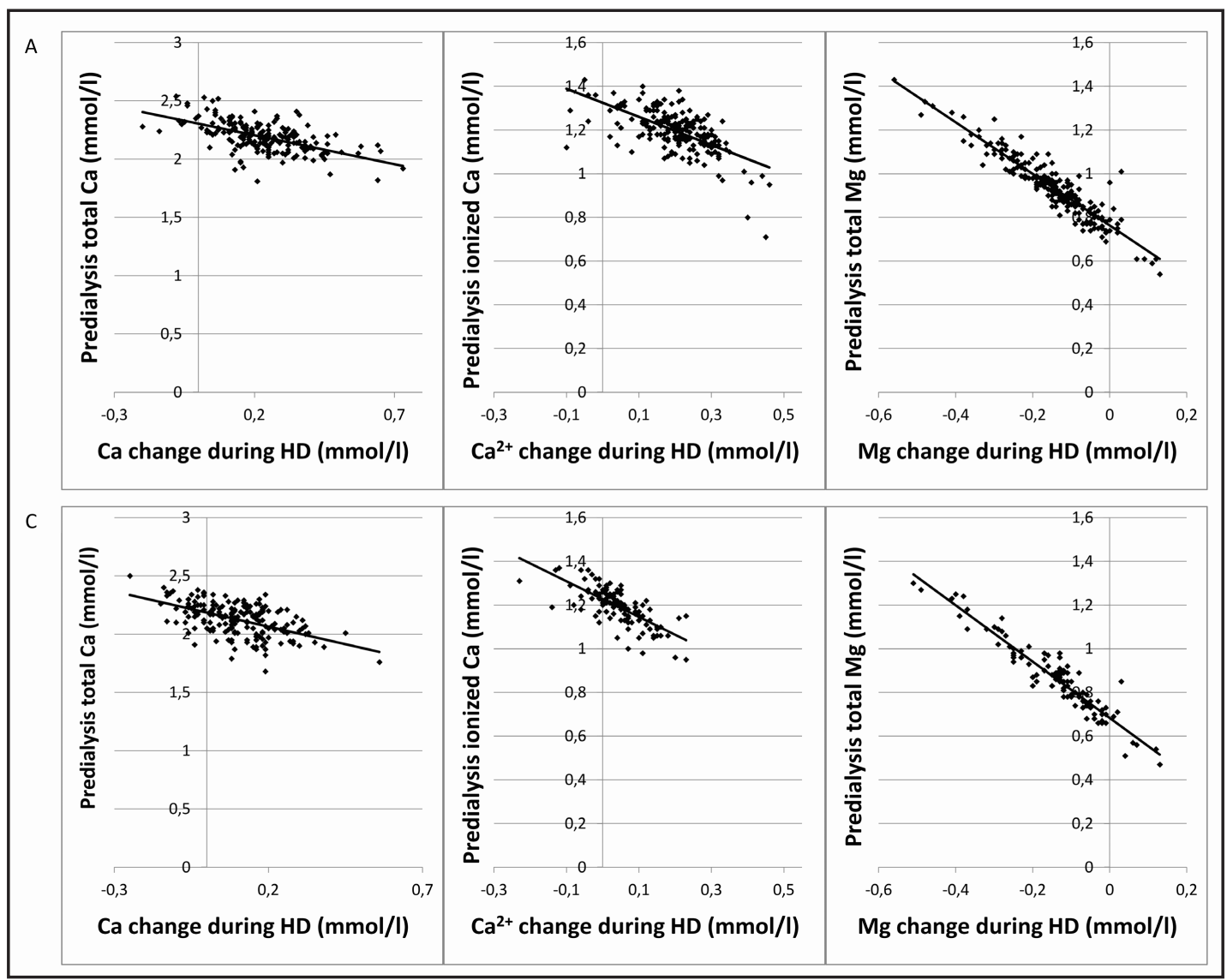

Fig. 1. Changes of serum calcium and magnesium during HD with dialysis solution with acetate (A) and citrate (C).

\section{Results}

Serum calcium changes

Both total $\mathrm{Ca}$ and $\mathrm{Ca}^{2+}$ serum concentrations increased in $97 \%$ of procedures with dialysis solutions $\mathrm{A}$ and in $76 \%$ of procedures with solution $\mathrm{C}$. The magnitude of this increase was significantly higher when solution A was used (Table 1). For solution A, serum calcium increased in patients with predialysis concentrations lower than $2.33 \mathrm{mmol} / \mathrm{L}$ for $\mathrm{Ca}$ and $1.33 \mathrm{mmol} / \mathrm{L}$ for $\mathrm{Ca}^{2+}$, respectively (Figure 1 ). In procedures with dialysis solution $\mathrm{C}$ these 


\section{Kidney Blood Pressure Research}

Table 2. Serum magnesium concentrations before and after HD and HDF procedures, comparison of two dialysis solutions: A - Dialysis solution with acetate, C - dialysis solution with citrate. All magnesium concentrations expressed in mmol/L. $\mathrm{Mg}$ - total magnesium, $\mathrm{Mg}^{2+}$ - ionized magnesium concentration. Data are given as median (interquartile range)

\begin{tabular}{lccc}
\hline Serum magnesium & \multicolumn{2}{c}{ Dialysis solution } & $\begin{array}{c}\text { Difference } \\
\text { between groups }\end{array}$ \\
\cline { 2 - 3 } concentrations & $\mathrm{A}$ & $\mathrm{C}$ & $\mathrm{p}<0.001$ \\
\hline Mg before procedure & $0.93(0.85 ; 1.02)$ & $0.85(0.76 ; 0.96)$ & $\mathrm{p}<0.000001$ \\
Mg after procedure & $0.78(0.76 ; 0.82)$ & $0.72(0.68 ; 0.77)$ & $\mathrm{p}<0.42$ \\
Mg change & $-0.14(-0.22 ;-0.08)$ & $-0.12(-0.21 ;-0.07)$ & $\mathrm{p}=0.26$ \\
Mg2+ before procedure & $0.52(0.44 ; 0.58)$ & $0.45(0.43 ; 0.49)$ & $\mathrm{p}<0.0003$ \\
Mg$^{2+}$ after procedure & $0.45(0.44 ; 0.48)$ & $0.38(0.36 ; 0.40)$ & $\mathrm{p}<0.24$ \\
Mg$^{2+}$ change & $-0.03(-0.11 ; 0.00)$ & $-0.07(-0.10 ;-0.03)$ & \\
\hline
\end{tabular}

"cut-off" concentrations were significantly lower - $2.19 \mathrm{mmol} / \mathrm{L}$ for Ca and $1.23 \mathrm{mmol} / \mathrm{L}$ for $\mathrm{Ca}^{2+}$ (Figure 1). Calculated ratio $\mathrm{Ca} / \mathrm{Ca}^{2+}$ decreased in procedures with A dialysate $(\mathrm{p}<0.00001)$, but did not change if solution $\mathrm{C}$ was used $(\mathrm{p}=0.48)$.

When we analyzed differences between HD and HDF procedures, a slightly higher increase of $\mathrm{Ca}$ in $\mathrm{HDF}$ was observed with solution $\mathrm{C}$, but not with solution A. Median Ca increase was $0.16(0.04 ; 0.25)$ in HDF and $0.08(0.00 ; 0.16) \mathrm{mmol} / \mathrm{L}$ in HD procedures with solution $C(p=0.01)$.

\section{Serum magnesium changes}

Analyzing predialysis values we found mild hypomagnesemia in $6 \%$ and mild hypermagnesemia in $17 \%$ patients. Extracorporeal elimination led to the increase of serum $\mathrm{Mg}$ (both total $\mathrm{Mg}$ as well as ionized fraction) only in $6 \%$ procedures with dialysis solution $\mathrm{A}$ and in $7 \%$ of procedures with solution $\mathrm{C}$. When solution $\mathrm{C}$ was used, postdialysis $\mathrm{Mg}$ and $\mathrm{Mg}^{2+}$ concentrations were significantly lower compared to dialysis solution A (Table 2). There was no difference between HD and HDF procedures.

For solution A, an increase was observed in patients with predialysis serum concentrations lower than $0.76 \mathrm{mmol} / \mathrm{L}$ for $\mathrm{Mg}$ and lower than $0.47 \mathrm{mmol} / \mathrm{L}$ for $\mathrm{Mg}^{2+}$ (Figure 1). These "cut-off" concentrations were significantly lower with dialysis solution C, being $0.68 \mathrm{mmol} / \mathrm{L}$ for $\mathrm{Mg}$ and $0.38 \mathrm{mmol} / \mathrm{L}$ for $\mathrm{Mg}^{2+}$ (Figure 1). There was no association between calcium and magnesium changes during procedures.

\section{Serum iPTH changes}

Predialysis serum iPTH concentrations were variable among patients. To see whether there was a different iPTH change during HD due to different dialysis solutions we analyzed data in cross-over design. PTH concentration decreased during procedures with solution A by $64 \%$; from $22.2(15.3 ; 36.3)$ to $8.0(5.9 ; 12.5) \mathrm{pmol} / \mathrm{L}(\mathrm{p}<0.0001)$. On the contrary, when solution $C$ was used, iPTH concentration increased insignificantly by $4 \%$ from 27.0 $(20.6 ; 36.9)$ to $28.0(21.5 ; 41.2) \mathrm{pmol} / \mathrm{L}(\mathrm{p}=0.06)$. However, an increase by more than $25 \%$ was observed in $28 \%$ procedures when dialysis solution $\mathrm{C}$ was used. Maximal increase was 13 and $87 \%$ when dialysis solution A and C was used, respectively. Changes of PTH during procedure negatively correlated significantly with serum $\mathrm{Ca}^{2+}$ changes $(\mathrm{R}=-0.26$ and -0.24 for solution $\mathrm{A}$ and $\mathrm{C}$, respectively) and also with $\mathrm{Mg}^{2+}$ changes $(\mathrm{R}=-0.21$ and -0.37 for solution A and C, respectively). There was no difference between HD and HDF procedures.

\section{Dialysis adequacy, serum phosphate and $p H$ changes}

Serum phosphate changes and $\mathrm{Kt} / \mathrm{V}$ values for procedures using $\mathrm{A}$ and $\mathrm{C}$ dialysis solutions are shown in Table 3. Data suggest higher Kt/V and $\mathrm{P}$ removal during HD with added citrate. 


\section{Kidney Blood Pressure Research}

Table 3. Serum phosphate concentrations before and after HD, comparison of two dialysis solutions: A Dialysis solution with acetate, $\mathrm{C}$ - dialysis solution with citrate. P - phosphate concentrations expressed in $\mathrm{mmol} / \mathrm{L}$

\begin{tabular}{lccc}
\hline Parameter & \multicolumn{2}{c}{ Dialysis solution } & Difference between \\
& A & $\mathrm{C}$ & groups \\
\hline preHD P & $1.70(1.40 ; 2.00)$ & $1.79(1.41 ; 2.10)$ & $\mathrm{p}=0.12$ \\
postHD P & $0.72(0.59 ; 0.84)$ & $0.72(0.59 ; 0.84)$ & $\mathrm{p}=0.74$ \\
P change & $-0.97(-1.24 ;-0.72)$ & $-1.08(-1.28 ;-0.81)$ & $\mathrm{p}=0.06$ \\
Kt/V & $1.52(1.34 ; 1.70)$ & $1.62(1.21 ; 1.65)$ & $\mathrm{p}=0.05$ \\
\hline
\end{tabular}

During HD with solution A, blood pH increased from 7.37 (7.35; 7.38) to 7.46 (7.44; 7.49). The increase was significantly higher when solution $C$ was used; $\mathrm{pH} 7.36(7.34 ; 7.37)$ before and $7.47(7.45 ; 7.49)$ after HD, $\mathrm{p}=0.002$.

\section{Discussion}

Our study clearly shows that substitution of part of acetate by citrate in dialysis solution significantly influences changes of serum calcium, magnesium and parathyroid hormone concentrations during HD and HDF procedures. Substantial differences between A and C solutions were observed despite the identical concentrations of $\mathrm{Ca}(1.5 \mathrm{mmol} / \mathrm{L})$ and $\mathrm{Mg}(0.5$ $\mathrm{mmol} / \mathrm{L}$ ) in both dialysis solutions.

Probable mechanism of described changes is the binding of calcium and magnesium to the citrate. Formed complexes are partially removed from blood through the membrane during dialysis. As only a small amount of citrate gets to the body, it is quickly metabolized. A higher increase in total calcium in HDF procedures with solution $\mathrm{C}$ might be due to an increase in concentration of Ca-citrate complexes in blood. As we have not measured citratemia, we cannot prove this in our present study. However, a higher increase in citratemia during HDF compared HD procedures with citrate dialysate was shown by Panichi et al. [2].

There is still no consensus regarding the optimal dialysate calcium concentration. KDIGO in its guidelines from 2009 suggests using a dialysate calcium concentration between 1.25 and $1.50 \mathrm{mmol} / \mathrm{L}$ [16]. Although individualization has been advocated, most centers use established dialysate calcium concentrations within the recommended range. In bicarbonate hemodialysis, calcium mass balance studies showed net positive transfer of Ca from dialysate to blood with $1.5 \mathrm{mmol} / \mathrm{L}$ and approximately neutral or slightly negative Ca flux with 1.25 $\mathrm{mmol} / \mathrm{L}$ dialysate $\mathrm{Ca}$ in most patients [17]. However, the main driving force responsible for calcium mass balance is diffusion gradient between ionized Ca in the blood and dialysate and ultrafiltration. Thus, Ca mass balance may differ widely depending on patients' factors. As a result, dialysate composition should be individualized, whenever possible, to meet specific patient's requirements. Our data suggest that citrate solution with low Ca concentration should not be used in patients with secondary hyperparathyroidism. Although, it might be used in adynamic bone disease to stimulate parathyroid activity.

Another important issue is the safety of the hemodialysis procedure. Lower dialysate calcium is associated with blood pressure decrease during HD [18] and sudden cardiac arrest [19]. Recent study shows that increases in the serum-to-dialysate calcium gradient proportionally increases the risk of peridialytic sudden cardiac arrest [20]. This issue was not addressed in our study, but we showed that a switch to dialysis solution with citrate increases serum-to-dialysate calcium gradient and may potentially increase the risk of adverse events in cardiac-compromised patients. Therefore, the use of higher calcium concentration in dialysate should be considered in high-risk patients. 


\section{Kidney Blood Pressure Research}

Higher HD efficiency and lower predialysis phosphate levels when citrate dialysate is used have been shown in larger studies [5]. Our study was not primarily designed to assess the effect of added citrate on phosphate removal and dialysis efficiency. Predialysis P levels were not fully comparable and higher P concentration may be responsible for higher phosphate decrease during the procedure. Pharmacological treatment that influences predialysis phosphate levels might be changed during study. However, our results are in concordance with other studies showing better phosphate removal and higher dialysis efficiency [5-6].

Magnesium is a crucial intracellular ion with high levels reported in chronic hemodialysis patients. Eg., in a group of hemodialysis patients with $\mathrm{Mg} 0.75 \mathrm{mmol} / \mathrm{L}$ in a dialysis solution mild hypermagnesemia (serum $\mathrm{Mg} \geq 1.15 \mathrm{mmol} / \mathrm{L}$ ) was found in $81 \%$ and significant hypermagnesemia (serum $\mathrm{Mg} \geq 1.5 \mathrm{mmol} / \mathrm{L}$ ) in $17 \%$ [21]. Hypermagnesemia was also found in $73 \%$ of patients dialyzed with $0.5 \mathrm{mmol} / \mathrm{L} \mathrm{Mg} \mathrm{[22].} \mathrm{In} \mathrm{our} \mathrm{study} \mathrm{we}$ found mild hypermagnesemia in only $17 \%$ and mild hypomagnesemia in $6 \%$ patients. Key determinants of serum magnesium levels are magnesium intake [21] and removal during $\mathrm{HD}$ [23]. We may only assume low intake in our patients with only $7 \%$ patients being on $\mathrm{Mg}$ containing medication.

Concentration of magnesium in dialysis solution affects the occurrence of muscle cramps during HD [23], intradialytic change of blood pressure [24], PTH concentrations and vascular calcifications [25]. Despite low serum magnesium concentrations found in our patients, its levels significantly decreased during HD. Moreover, postdialysis $\mathrm{Mg}$ concentrations were significantly lower when dialysis solution C was used. Therefore, higher magnesium concentration in solution $\mathrm{C}$ might be more appropriate for our patients. A decrease in magnesium concentration during HD, together with only a small increase of Ca during HD with solution C, may explain increased frequency of muscle cramps observed in recent study by Rocha and colleagues [10]. We observed a clinically small, albeit statistically significant, higher increase in $\mathrm{pH}$ when solution $\mathrm{C}$ was used. The real difference in serum $\mathrm{pH}$ between solutions was 0.02 and can only clinically insignificantly influence concentrations of free fraction of $\mathrm{Mg}$ [26].

A decrease of serum PTH hormone during conventional bicarbonate hemodialysis and hemodiafiltration with solution A containing $1.5 \mathrm{mmol} / \mathrm{L}$ calcium is not surprising. Serum calcium increase is physiologically associated with immediate PTH decrease. We have confirmed that this association is preserved in our group of hemodialysis patients, i.e. that parathyroid tissue is sensitive to immediate calcium load. This may have an important implication for long-term therapy of secondary hyperparathyroidism: serum calcium changes are mediated through calcium sensing receptor (CaR) on parathyroid glands, and our data indirectly confirms well preserved function of these receptors.

Serum magnesium is also involved in immediate PTH regulation: it influences CaR in similar manner, but with less affinity. However, as we observed a decrease and not an increase of serum magnesium during procedures, serum magnesium changes did not participate on the PTH decrease. It is possible, that dialysis solution with higher magnesium concentration, which would enable serum magnesium increase, would further decrease serum PTH. In our study, dialysis solution A is associated with temporary serum PTH decrease despite concomitant decrease in serum magnesium concentration.

Conversely, the same dialysate calcium concentration $(1.5 \mathrm{mmol} / \mathrm{L})$ in solution $\mathrm{C}$ was not able to decrease serum PTH during procedures (neither HD, nor HDF). All dialysate calcium is diffusible. This indicates that the balance using $1.5 \mathrm{mmol} / \mathrm{l}$ of calcium in dialysate should always be positive. Using $\mathrm{C}$ solution led to much less of a positive balance and was associated with much a lower increase of postdialysis serum calcium concentration. This means that part of the calcium did not reach systemic circulation. It is reasonable to assume that the citrate-calcium complexes were formed and then partially lost into dialysate. An important implication for clinical practice is that $1.5 \mathrm{mmol} / \mathrm{L} \mathrm{Ca}$ in dialysis solution $\mathrm{C}$ does not suppress PTH and these patients should likely be treated with additional means aiming to influence CaR. 


\section{Kidney \\ Blood Pressure Research}

Šafránek/Moučka/Vávrová et al.: Citrate-Enriched Hemodialysis Solution

We also analyzed whether type of procedure (HD versus HDF) has different effect on iPTH change during dialysis. Either with solution A or C, we found no significant difference. This is in concordance with recent finding of Grundstrom et al. and indicates that hemodialysis and hemodiafiltration per se have similar effect on serum parathyroid hormone concentration [13].

\section{Conclusion}

Our study is the first one that clearly shows the different effect between A and C solution on concomitant immediate changes in serum calcium, magnesium and PTH. It has an important clinical implication: composition of dialysis solution should be an integral part of strategy in how to prevent and treat secondary hyperparathyroidism. This is true not only for dialysate calcium and magnesium, but also for additive components - such as citrate versus acetate.

Dialysis solution with citrate has been shown to have different specific effects. Its use leads to decreased peripheral resistance, blood pressure, coagulation in extracorporeal circuit, decrease in calcium, magnesium and increase in PTH concentrations. Availability of this type of dialysis solution may help physicians to provide appropriated dialysis to patients with specific requirements. Our study shows that acute effects on calcium, magnesium and PTH concentrations are significant and must be taken into account. Concentrations of calcium and magnesium in dialysis solution should be adjusted accordingly. However, beneficial effects of citrate solution must be proven in long term studies.

\section{Disclosure Statement}

None.

\section{Acknowledgements}

Study was supported by Research Project NT/11355-4/2010 Ministry of Health of the Czech Republic.

\section{References}

1 Mansell MA, Wing AJ: Acetate or bicarbonate for haemodialysis? Br Med J 1983;287:308-309.

-2 Panichi V, Fiaccadori E, Rosati A, Fanelli R, Bernabini G, Scatena A, Pizzarelli F: Post-dilution on line haemodiafiltration with citrate dialysate: first clinical experience in chronic dialysis patients. Scientific World Journal 2013;2013:703612.

-3 Pizzarelli F, Cerrai T, Dattolo P, Ferro G: On-line haemodiafiltration with and without acetate. Nephrol Dial Transplant 2006;21:1648-1651.

4 Ahmad S, Callan R, Cole JJ, Blagg CR: Dialysate made from dry chemicals using citric acid increases dialysis dose. Am J Kidney Dis 2000;35:493-499.

-5 Kossmann RJ, Gonzales A, Callan R, Ahmad S: Increased efficiency of hemodialysis with citrate dialysate: a prospective controlled study. Clin J Am Soc Nephrol 2009;4:1459-1464.

6 Gabutti L, Lucchini B, Marone C, Alberio L, Burnier M: Citrate- vs. acetate-based dialysate in bicarbonate haemodialysis: consequencec on haemodynamics, coagulation, acid-base status, and electrolytes. BMC Nephrol 2009;10:7.

-7 Aniort J, Petitclerc T, Creput C: Safe use of citric acid-based dialysate and heparin removal in postdilution online hemodiafiltration. Blood Purif 2012;34:336-343. 


\section{Kidney \\ Blood Pressure Research}

Šafránek/Moučka/Vávrová et al.: Citrate-Enriched Hemodialysis Solution

8 Sands JJ, Kotanko P, Segal JH, Ho ChH, Usvat L, Young A, Carter M, Sergeyeva O, Korth L, Maunsell E, Zhu Y, Krishnan M, Diaz-Buxo JA: Effects of citrate acid concentrate (Citrasate) on Heparin N requirements and hemodialysis adequacy: a multicenter, prospective noninferiority trial. Blood Purif 2012;33:199-204.

-9 Stegmayr BG, Jonsson P, Mahmood D: A significant proportion of patients treated with citrate containing dialysate need additional anticoagulation. Int J Artif Organs 2013;36:1-6.

10 Rocha AD, Padua VC, Oliveira E, Guimaraes MM, Lugon JR, Strogoff de Matos JP: Effects of citrate-enriched bicarbonate based dialysate on anticoagulation and dialyzer reuse in maintenance hemodialysis patients. Hemodial Int 2014;18:467-472.

-11 Gritters M, Grooteman MP, Schoorl M, Schoorl M, Bartels PCM, Scheffer PG, Teerlink T, Schalkwijk CG, Spreeuwenberg M, Nube MJ: Citrate anticoagulation abolishes degranulation of polymorphonuclear cells and platelets and reduces oxidative stress during haemodialysis. Nephrol Dial Transplant 2006;21:153159.

12 Bohler J, Schollmeyer P, Dressel B, Dobos G, Horl WH: Reduction of granulocyte activation during hemodialysis with regional citrate anticoagulation: dissociation of complement activation and neutropenia from neutrophil degranulation. J Am Soc Nephrol 1996;7:234-241.

13 Grundstrom G, Christensson A, Alquist M, Nilsson LG, Segelmark M: Replacement of acetate with citrate in dialysis fluid: a randomized clinical trial of short term safety and fluid biocompatibility. BMC Nephrol 2013;14:216.

14 Daugirdas JT: Second generation logarithmic estimates of single-pool variable volume Kt/V: An analysis of error. J Am Soc Nephrol 1993;4:1205-1213.

15 Clinical practice guidelines for hemodialysis adequacy, update 2006. Am J Kidney Dis 2006;48:S2-90.

$\checkmark 16$ Kidney Disease: Improving Global Outcomes (KDIGO) CKD-MBD Work Group: KDIGO clinical practice guideline for the diagnosis, evaluation, prevention, and treatment of chronic kidney disease-mineral and bone disorder (CKD-MBD). Kidney Int 2009;76:S1-S130.

-17 Bosticardo G, Malberti F, Basile C, Leardini L, Libutti P, Filiberti O, Schillaci E, Ravani P: Optimizing the dialysate calcium concentration in bicarbonate haemodialysis. Nephrol Dial Transplant 2012;27:24892496.

18 van der Sande FM, Cheriex EC, Willibrord HM, van Kuijk WHM, Leunissen KML: Effect of dialysate calcium concentrations on intradialytic blood pressure course in cardiac-compromised patients. Am J Kidney Dis 1998;32:125-131.

19 Pun P, Lehrich RW, Honeycutt EF, Herzog CA, Middleton JP: Modifiable risk factors associated with sudden cardiac arrest within hemodialysis clinics. Kidney Int 2011;79:218-227.

20 Pun PH, Horton JR, Middleton JP: Dialysate calcium concentration and the risk of sudden cardiac arrest in hemodialysis patients. Clin J Am Soc Nephrol 2013;8:797-803.

21 Wyskida K, Witkowicz J, Chudek J, Wiecek A: Daily magnesium intake and hypermagnesemia in hemodialysis patients with chronic kidney disease. J Ren Nutr 2012;22:19-26.

22 Navarro JF, Mora C, Jimenez A, Torres A, Macia M, Garcia J: Relationship between serum magnesium and parathyroid hormone levels in hemodialysis patients. Am J Kidney Dis 1999;34:43-48.

-23 Kelber J, Slatopolsky E, Delmez JA: Acute effects of different concentrations of dialysate magnesium during high-efficiency dialysis. Am J Kidney Dis 1994;24:453-460.

-24 Kyriazis J, Kalogeropoulou K, Bilirakis L, Smirnioudis N, Pikounis V, Stamatiadis D, Liolia E: Dialysate magnesium level and blood pressure. Kidney Int 2004;66:1221-1231.

25 Floege J: Magnesium in CKD: more than a calcification inhibitor? J Nephrol DOI 10.1007/s40620-0140140-6.

26 Thode J, Nistrup Holmegsard S, Transbel I, Fogh-Anderse N, Siggasard-Andersen O: Adjusted ionized calcium (at pH 7.4) and actual ionized calcium (at actual pH) in capillary blood compared for clinical evaluation of patients with disorders of calcium metabolism. Clin Chem 1990;36:541-544. 